\title{
The association between polymorphisms in microRNA genes and cervical cancer in a Chinese Han population
}

\author{
Li Chuanyin ${ }^{1, *}$, Wang Xiaona ${ }^{1, *}$, Yan Zhiling ${ }^{2}$, Zhang Yu ${ }^{1}$, Liu Shuyuan ${ }^{1}$, Yang Jie ${ }^{3}$, \\ Hong Chao ${ }^{1}$, Shi $\mathrm{Li}^{1}$, Yang Hongying ${ }^{2}$ and Yao Yufeng ${ }^{1}$ \\ ${ }^{1}$ Institute of Medical Biology, Chinese Academy of Medical Sciences \& Peking Union Medical College, Kunming 650118, China \\ ${ }^{2}$ Department of Gynaecologic Oncology, The 3rd Affiliated Hospital of Kunming Medical University, Kunming 650118, China \\ ${ }^{3}$ Wenzhou Medical University, Wenzhou 325035, China \\ "These authors have contributed equally to this work \\ Correspondence to: Shi Li, email: shili.imb@gmail.com \\ Yang Hongying, email: jyahy@tom.com \\ Yao Yufeng, email: leoyyf@gmail.com
}

Keywords: association study, cervical cancer, microRNA, single nucleotide polymorphisms, Chinese Han population

Received: June 22, $2017 \quad$ Accepted: August 27, $2017 \quad$ Published: September 23, 2017

Copyright: Chuanyin et al. This is an open-access article distributed under the terms of the Creative Commons Attribution License 3.0 (CC BY 3.0), which permits unrestricted use, distribution, and reproduction in any medium, provided the original author and source are credited.

\section{ABSTRACT}

Several studies have confirmed the crucial roles of microRNAs (miRNAs) in cancer occurrence. In addition, single nucleotide polymorphisms (SNPs) in miRNA genes have been associated with various cancers. The aim of the present study was to investigate the association of SNPs in miRNA genes with cervical intraepithelial neoplasia (CIN) and cervical cancer in a Chinese Han population. We searched SNPs in nineteen miRNAs by sequencing healthy individuals $(n=50)$. Then, a total of 400 patients with CIN, 609 patients with cervical cancer and 583 healthy individuals were recruited to genotype the SNPs using a Taqman assay. The results showed that only five of the nineteen miRNAs had SNPs (rs11134527 in pri-miR-218-2; rs74693964 in pri-miR-145; rs6062251 in pri-miR-133a2; rs531564 in pri-miR-124-1; and rs1834306 in pri-miR-100) in this Chinese Han population. The frequency of the rs11134527A allele was significantly higher in the control group than in CIN and cervical cancer groups ( $P=0.011$ and 0.035 , respectively). The frequency of the rs531564G allele was higher in the CIN and control groups than in the cervical cancer group $(P=0.019$ and 0.017, respectively). These results indicated that rs11134527 in pri-miR-218-2 and rs531564 in pri-miR-124-1 could be associated with CIN and cervical cancer in the Chinese Han population.

\section{INTRODUCTION}

Cervical cancer is one of the most common malignancies in women worldwide, with an estimated global incidence of 470,000 new cases and approximately 233,000 deaths per year [1]. Compared to developed countries, the incidence and mortality of cervical cancer is higher in low-resource countries [2]. High-risk human papillomavirus (HPV) infections are the main aetiological factors of cervical intraepithelial neoplasia
(CIN) in women, and persisting high-risk HPV infections significantly facilitate the development of CIN to cervical cancer. However, evidence suggests that host genetic factors are also involved in the initiation and development of cervical cancer [3-5].

MicroRNAs (miRNAs) are a group of short RNAs with 20-23 noncoding nucleotides. MiRNAs play important roles in various biological processes through binding to the 3'-untranslate region (UTR) of target mRNAs and inhibiting protein translation or degrading 
Table 1: The characteristics of the subjects in the present subjects

\begin{tabular}{lcccc}
\hline & Cervical cancer & CIN & Control & P value \\
\hline $\mathrm{N}$ & 609 & 400 & 583 & 0.345 \\
Ages & $44.22 \pm 9.08$ & $43.46 \pm 9.25$ & $43.89 \pm 5.93$ & \\
Pathologic types & & & & \\
SCC & 501 & & & \\
AC & 91 & & \\
Others & 17 & & \\
\hline
\end{tabular}

mRNAs. MiRNAs regulate more than $60 \%$ of all human genes [6] and are involved in crucial physiological processes, such as proliferation, apoptosis, differentiation, tumourigenesis and cancer metastasis [7-10].

Recent studies have demonstrated the aberrant expression of miRNAs in cervical cancer and their contribution to tumour generation [11]. Functional studies have shown that miRNAs impact tumour cell fate through the regulation of various cell signalling pathways [12]. Thus, miRNAs act as oncogenic or anti-oncogenic molecules in the initiation and development of cervical cancer [13]. For example, miR-218 functions as a tumour suppressor through targeting focal adhesion pathways and the SLIT2-ROBO1 pathway, and inhibiting cancer cell migration and invasion. Single nucleotide polymorphisms (SNPs) in miRNA genes have been associated with various human diseases [14-16]. In 2016, Wang et al. reported that rs767649 in miR-155 is associated with cervical cancer [17].

In the present study, we searched for SNPs in nineteen miRNAs associated with cervical cancer [18]. Subsequently, we conducted an association study in patients with CIN, patients with cervical cancer and healthy individuals to investigate the relationship of the SNPs in miRNAs with CIN and cervical cancer in a Chinese Han population.

\section{RESULTS}

\section{Subject characteristics}

Table 1 lists the characteristics of subjects in the present study. There was no significant difference in age between CIN, cervical cancer and control groups $(p>0.05)$. In the cervical cancer group, there were 91 individuals with adenocarcinoma (AC), 501 individuals with squamous cell carcinoma (SCC) and 17 individuals with other pathological types.

\section{The sequencing results of nineteen miRNA genes}

Five of the nineteen miRNAs showed polymorphisms in 50 healthy individuals. The polymorphisms are rs11134527 in pri-miR-218-2, rs74693964 in pri-miR-145, rs6062251 in pri-miR-133a2, rs531564 in pri-miR-124-1 and rs1834306 in pri-miR-100.

\section{Association of the five SNPs with cervical cancer}

The allelic and genotypic frequencies for the five SNPs in miRNAs are displayed in Tables 2 and 3, respectively. All five SNPs were in Hardy-Weinberg equilibrium (HWE) in the control group $(P>0.05)$. The A allelic frequency of rs11134527 in CIN (59.3\%) and cervical cancer $(60.8 \%)$ groups was significantly different from that in the control group $(64.9 \%)(P=0.011$ and 0.035 , respectively), and the A allele occurred more frequently in the control group compared with the CIN $(\mathrm{OR}=0.786 ; 95 \% \mathrm{CI}: 0.653-0.946)$ and cervical cancer groups $(\mathrm{OR}=0.836$; 95\%CI: $0.708-0.988)$. The $\mathrm{C}$ allelic frequency of rs531564 in the cervical cancer group $(14.6 \%)$ was significantly different from that in the control (11.3\%) and CIN groups $(11.0 \%)(P=0.017$ and 0.019 , respectively), and the $\mathrm{C}$ allele occurred more frequently in the cervical cancer group compared to the control groups $(\mathrm{OR}=1.341 ; 95 \% \mathrm{CI}: 1.054-1.706)$ and CIN (OR=1.385;95\%CI:1.054-1.819). The genotypic frequencies of rs11134527 (A/A, 36.7\%; A/G, 45.0\%; and $\mathrm{G} / \mathrm{G}, 18.2 \%)$ and rs6062251 (C/C, 8.5\%; C/T, 51.7\%; and $\mathrm{T} / \mathrm{T}, 39.8 \%$ ) in the CIN group were significantly different from those in the control $(\mathrm{A} / \mathrm{A}, 41.5 \%$; $\mathrm{A} / \mathrm{G}, 46.8 \%$; and $\mathrm{G} / \mathrm{G}, 11.7 \%)(P=0.013)$ and cervical cancer groups $(\mathrm{C} / \mathrm{C}, 12.8 \%$; $\mathrm{C} / \mathrm{T}, 42.5 \%$; and $\mathrm{T} / \mathrm{T}, 44.7 \%)(P=0.007)$, respectively. Moreover, the genotypic frequencies of rs531564 in the cervical cancer group (C/C,2.8\%; $\mathrm{C} / \mathrm{G}, 23.6 \%$; and $\mathrm{G} / \mathrm{G}, 73.6 \%$ ) were significantly different from that in the $\mathrm{CIN}(\mathrm{C} / \mathrm{C}, 1.0 \% ; \mathrm{C} / \mathrm{G}, 20.0 \%$; and $\mathrm{G} / \mathrm{G}, 79.0 \%$ ) and control groups $(\mathrm{C} / \mathrm{C}, 1.2 \%$; $\mathrm{C} / \mathrm{G}, 20.2 \%$; and $\mathrm{G} / \mathrm{G}, 78.6 \%)(P=0.047$ and 0.043 , respectively). The allelic and genotypic frequencies of rs74693964 and rs 1834306 were not significantly different among the three groups.

\section{Model of inheritance analysis}

Tables 4-6 present the results of the analyses of different models of inheritance for the five SNPs. The Akaike information criterion (AIC) and Bayesian 
Table 2: Allelic frequencies comparison of the five SNPs among control, CIN and cervical cancer groups

\begin{tabular}{|c|c|c|c|c|c|c|c|c|}
\hline \multirow{3}{*}{$\begin{array}{l}\text { SNPs } \\
\text { rs11134527 }\end{array}$} & \multirow{2}{*}{\multicolumn{2}{|c|}{$\operatorname{Alleles}(n, \%)$}} & \multicolumn{2}{|c|}{ Control VS CIN } & \multicolumn{2}{|c|}{ CIN VS cervical cancer } & \multicolumn{2}{|c|}{ Control VS cervical cancer } \\
\hline & & & $P$ value & OR $[95 \% \mathrm{CI}]$ & $P$ value & OR[95\%CI] & $P$ value & OR[95\%CI] \\
\hline & A & G & \multirow{4}{*}{0.011} & \multirow{4}{*}{$0.786[0.653-0.946]$} & \multirow{4}{*}{0.499} & \multirow{4}{*}{$1.065[0.888-1.277]$} & \multirow{4}{*}{0.035} & \multirow{4}{*}{$0.836[0.708-0.988]$} \\
\hline Control & $757(64.9 \%)$ & $409(35.1 \%)$ & & & & & & \\
\hline $\mathrm{CIN}$ & $474(59.3 \%)$ & $326(40.7 \%)$ & & & & & & \\
\hline Cervical cancer & $740(60.8 \%)$ & $478(39.2 \%)$ & & & & & & \\
\hline rs74693964 & $\mathrm{C}$ & $\mathrm{T}$ & \multirow{4}{*}{0.502} & \multirow{4}{*}{$1.187[0.719-1.960]$} & \multirow{4}{*}{0.585} & \multirow{4}{*}{$1.158[0.684-1.963]$} & \multirow{4}{*}{0.174} & \multirow{4}{*}{$1.375[0.867-2.180]$} \\
\hline Control & $1123(96.3 \%)$ & $43(3.7 \%)$ & & & & & & \\
\hline CIN & $775(96.9 \%)$ & $25(3.1 \%)$ & & & & & & \\
\hline Cervical cancer & $1185(97.3 \%)$ & $33(2.7 \%)$ & & & & & & \\
\hline rs6062251 & $\mathrm{C}$ & $\mathrm{T}$ & \multirow{4}{*}{0.912} & \multirow{4}{*}{$1.011[0.836-1.222]$} & \multirow{4}{*}{0.888} & \multirow{4}{*}{$0.987[0.818-1.191]$} & \multirow{4}{*}{0.975} & \multirow{4}{*}{$0.997[0.842-1.181]$} \\
\hline Control & $398(34.1 \%)$ & $768(65.9 \%)$ & & & & & & \\
\hline CIN & $275(34.4 \%)$ & $525(65.6 \%)$ & & & & & & \\
\hline Cervical cancer & $415(34.1 \%)$ & $803(65.9 \%)$ & & & & & & \\
\hline rs531564 & $\mathrm{C}$ & G & \multirow{4}{*}{0.825} & \multirow{4}{*}{$0.968[0.727-1.289]$} & \multirow{4}{*}{0.019} & \multirow{4}{*}{$1.385[1.054-1.819]$} & \multirow{4}{*}{0.017} & \multirow{4}{*}{$1.341[1.054-1.706]$} \\
\hline Control & $132(11.3 \%)$ & $1034(88.7 \%)$ & & & & & & \\
\hline CIN & $88(11.0 \%)$ & $712(89.0 \%)$ & & & & & & \\
\hline Cervical cancer & $178(14.6 \%)$ & $1040(85.4 \%)$ & & & & & & \\
\hline rs1834306 & A & G & \multirow{4}{*}{0.964} & \multirow{4}{*}{$1.004[0.838-1.203]$} & \multirow{4}{*}{0.701} & \multirow{4}{*}{$1.036[0.866-1.238]$} & \multirow{4}{*}{0.634} & \\
\hline Control & $541(46.4 \%)$ & $625(53.6 \%)$ & & & & & & 211] \\
\hline $\mathrm{CIN}$ & $372(46.5 \%)$ & $428(53.5 \%)$ & & & & & & $1.040[0.000-1.221]$ \\
\hline Cervical cancer & $577(47.4 \%)$ & $641(52.6 \%)$ & & & & & & \\
\hline
\end{tabular}

information criterion (BIC) were calculated to identify the best inheritance model for each SNP. The model with smallest AIC and BIC values was the best-fit inheritance model. The genotypic frequency of rs $11134527 \mathrm{~A} / \mathrm{A}-\mathrm{A} / \mathrm{G}$ was significantly different from $\mathrm{G} / \mathrm{G}(P=0.018)$ under the recessive model between control and CIN groups. In this model, the $\mathrm{A} / \mathrm{A}-\mathrm{A} / \mathrm{G}$ genotype was associated with a decreased risk of $\mathrm{CIN}(\mathrm{OR}=0.61$; 95\%CI: 0.41-0.92). A comparison between $\mathrm{CIN}$ and cervical cancer groups revealed that the genotypic frequencies of rs6062251 were significantly different in the overdominant model $(P=0.007)$. In the overdominant model, the T/T-C/C genotype of rs6062251 was associated with increased risk of cervical cancer $\quad(\mathrm{OR}=1.45 ; \quad 95 \% \mathrm{CI}: 1.11-1.90)$. A comparison of control and cervical cancer groups revealed that the genotypic frequencies of rs531564 were significantly different in the log-additive model $(P=0.022)$. In this model, the genotype $2 \mathrm{G} / \mathrm{G}-\mathrm{C} / \mathrm{G}$ of $\mathrm{rs} 531564(\mathrm{OR}=0.75 ; 95 \% \mathrm{CI}$ : 0.58-0.96) was associated with a decreased risk of cervical cancer.

\section{DISCUSSION}

Evidence has shown that miRNAs are involved in the initiation and development of various types of cancers, and these molecules function as antioncogenes or oncogenes. SNPs in miRNAs, including primary, precursor and mature miRNA, may change the expression level and alter the binding affinity of miRNAs, and further regulate the expression of the target genes, thereby markedly impacting cell pathway regulation, which defines cellular fates $[19,20]$. In the present study, we observed that rs11134527 in pri-miR-218-2 and rs531564 in pri-miR-124-1 were associated with CIN and cervical cancer in a Chinese Han population.

In 2013, Yamamoto $\mathrm{N}$ et al. reported that the expression of miR-218 was significantly lower in cervical cancer tissues than in adjacent non-cancerous tissues, and the restoration of miR-218 significantly inhibited cancer cell proliferation, migration and invasion [21]. In addition, the anti-oncogene function of miR-218 has been reported in several types of cancers through targeting several oncogenes, such as Rictor (oral cancer), EGFR (non-small cell lung cancer), ROBO1 receptor (gastric cancer) and LAMB3 (cervical cancer) [22-25]. Several studies have investigated the association of rs11134527 with different diseases (Table 7) [26-28]; however, these studies provided contradictory results. In the present study, rs11134527 in pri-miR-218-2 was associated with CIN 
Table 3: Genotypic frequencies comparison of the five SNPs among control, CIN and cervical cancer groups

\begin{tabular}{|c|c|c|c|c|c|c|}
\hline \multirow{3}{*}{$\begin{array}{l}\text { SNPs } \\
\text { rs11134527 }\end{array}$} & \multirow{2}{*}{\multicolumn{3}{|c|}{$\operatorname{Genotypes}(n, \%)$}} & \multicolumn{3}{|c|}{$P$ value } \\
\hline & & & & \multirow[t]{2}{*}{ Control VS CIN } & \multirow[t]{2}{*}{ CIN VS cervical cancer } & \multirow[t]{2}{*}{ Control VS cervical cancer } \\
\hline & $\mathrm{A} / \mathrm{A}$ & $\mathrm{A} / \mathrm{G}$ & $\mathrm{G} / \mathrm{G}$ & & & \\
\hline Control & $242(41.5 \%)$ & $273(46.8 \%)$ & $68(11.7 \%)$ & & & \\
\hline $\mathrm{CIN}$ & $147(36.7 \%)$ & $180(45.0 \%)$ & $73(18.2 \%)$ & 0.013 & 0.366 & 0.101 \\
\hline Cervical cancer & $233(36.6 \%)$ & $294(48.3 \%)$ & $92(15.1 \%)$ & & & \\
\hline rs74693964 & $\mathrm{C} / \mathrm{C}$ & $\mathrm{C} / \mathrm{T}$ & $\mathrm{T} / \mathrm{T}$ & & & \\
\hline Control & $541(92.8 \%)$ & $41(7.0 \%)$ & $1(0.2 \%)$ & & & \\
\hline CIN & $376(94.0 \%)$ & $23(5.8 \%)$ & $1(0.3 \%)$ & 0.702 & 0.454 & 0.302 \\
\hline Cervical cancer & $576(94.6 \%)$ & $33(5.4 \%)$ & $0(0.0 \%)$ & & & \\
\hline rs 6062251 & $\mathrm{C} / \mathrm{C}$ & $\mathrm{C} / \mathrm{T}$ & $\mathrm{T} / \mathrm{T}$ & & & \\
\hline Control & $63(10.8 \%)$ & $272(46.7 \%)$ & $248(42.5 \%)$ & & & \\
\hline $\mathrm{CIN}$ & $34(8.5 \%)$ & $207(51.7 \%)$ & $159(39.8 \%)$ & 0.225 & 0.007 & 0.293 \\
\hline Cervical cancer & $78(12.8 \%)$ & $259(42.5 \%)$ & $272(44.7 \%)$ & & & \\
\hline rs531564 & $\mathrm{C} / \mathrm{C}$ & $\mathrm{C} / \mathrm{G}$ & $\mathrm{G} / \mathrm{G}$ & & & \\
\hline Control & $7(1.2 \%)$ & $118(20.2 \%)$ & $458(78.6 \%)$ & 0.952 & 0.047 & 0.043 \\
\hline $\mathrm{CIN}$ & $4(1.0 \%)$ & $80(20.0 \%)$ & $316(79.0 \%)$ & & & \\
\hline Cervical cancer & $17(2.8 \%)$ & $144(23.6 \%)$ & $448(73.6 \%)$ & & & \\
\hline rs1834306 & $\mathrm{A} / \mathrm{A}$ & $\mathrm{A} / \mathrm{G}$ & $\mathrm{G} / \mathrm{G}$ & & & \\
\hline Control & $126(21.6 \%)$ & $289(49.6 \%)$ & $168(28.8 \%)$ & & & \\
\hline CIN & $91(22.8 \%)$ & $190(47.5 \%)$ & $119(29.7 \%)$ & 0.811 & 0.834 & 0.875 \\
\hline Cervical cancer & $139(22.8 \%)$ & $299(49.1 \%)$ & $171(28.1 \%)$ & & & \\
\hline
\end{tabular}

and cervical cancer in a Chinese Han population, and the A allele of rs11134527 was associated with a lower risk of CIN $(P=0.011 ; \mathrm{OR}=0.786 ; 95 \% \mathrm{CI}: 0.653-0.946)$ and cervical cancer $(P=0.035 ; \mathrm{OR}=0.836 ; 95 \% \mathrm{CI}: 0.708-0.988)$ in a comparison of CIN and cervical cancer groups with control group. The genotype A/A-A/G showed a lower risk of cervical cancer compared with the $\mathrm{G} / \mathrm{G}$ genotype using the recessive model in a comparison of the CIN group with the control group $(P=0.018 ; \mathrm{OR}=0.61 ; 95 \% \mathrm{CI}: 0.41-0.92)$. However, this result was inconsistent with Shi et al. [28] whose study showed that the G/G genotype was associated with a decreased risk of cervical cancer compared with AA and $\mathrm{A} / \mathrm{G}$ genotypes. The discrepancy between these results might reflect different sample sizes and populations in the two studies, and unfortunately, the Shi et al. study did not focus on the association with CIN, thus, we could not compare the results between CIN and the control. In the present study, the allelic frequencies of rs11134527 were only significantly different in the comparison of CIN and cervical cancer groups with control group, but not in the comparison of CIN group with cervical cancer group.

Recent studies have reported that miR-124 suppresses a series of genes involved in the growth of human cancers. MiR-124 suppresses tumour growth through targeting STAT3 in colorectal cancer [29], CD151 in breast cancer [30], and ERK in cutaneous squamous cell carcinoma [31]. In cervical cancer, Wan et al. reported that miR-124 represses vasculogenic mimicry and cell motility by targeting amotL1 [32], and Zhang et al. showed that miR-124 inhibits the proliferation, invasion, migration and epithelial-mesenchymal transition of cervical cancer [33]. As an anti-oncogene, significantly lower miR-124 expression was detected in cervical cancer than in lowgrade squamous intraepithelial lesions [34]. Studies have shown that SNPs in miRNA genes might alter miRNA expression or function $[35,36]$. Thus, SNPs in miR-124 might be associated with miR-124 expression and are further associated with cervical cancer. Rs531564 has been significantly correlated with the risk of various cancers (Table 7), including cervical cancer and oesophageal squamous cell carcinoma (ESCC) $[26,37,38]$. In the present study, rs531564 in pri-miR-124-1 was associated with cervical cancer risk $(P=0.017, \mathrm{OR}=1.341 ; 95 \% \mathrm{CI}$ : 1.054-1.706). Additionally, this SNP was correlated with the progression from $\mathrm{CIN}$ to cervical cancer $(P=0.019$; $\mathrm{OR}=1.385 ; 95 \% \mathrm{CI}: 1.054 \sim 1.819)$. These results were 
Table 4: Different inheritance models analysis of the SNPs in miRNA genes in the comparison between control and CIN groups

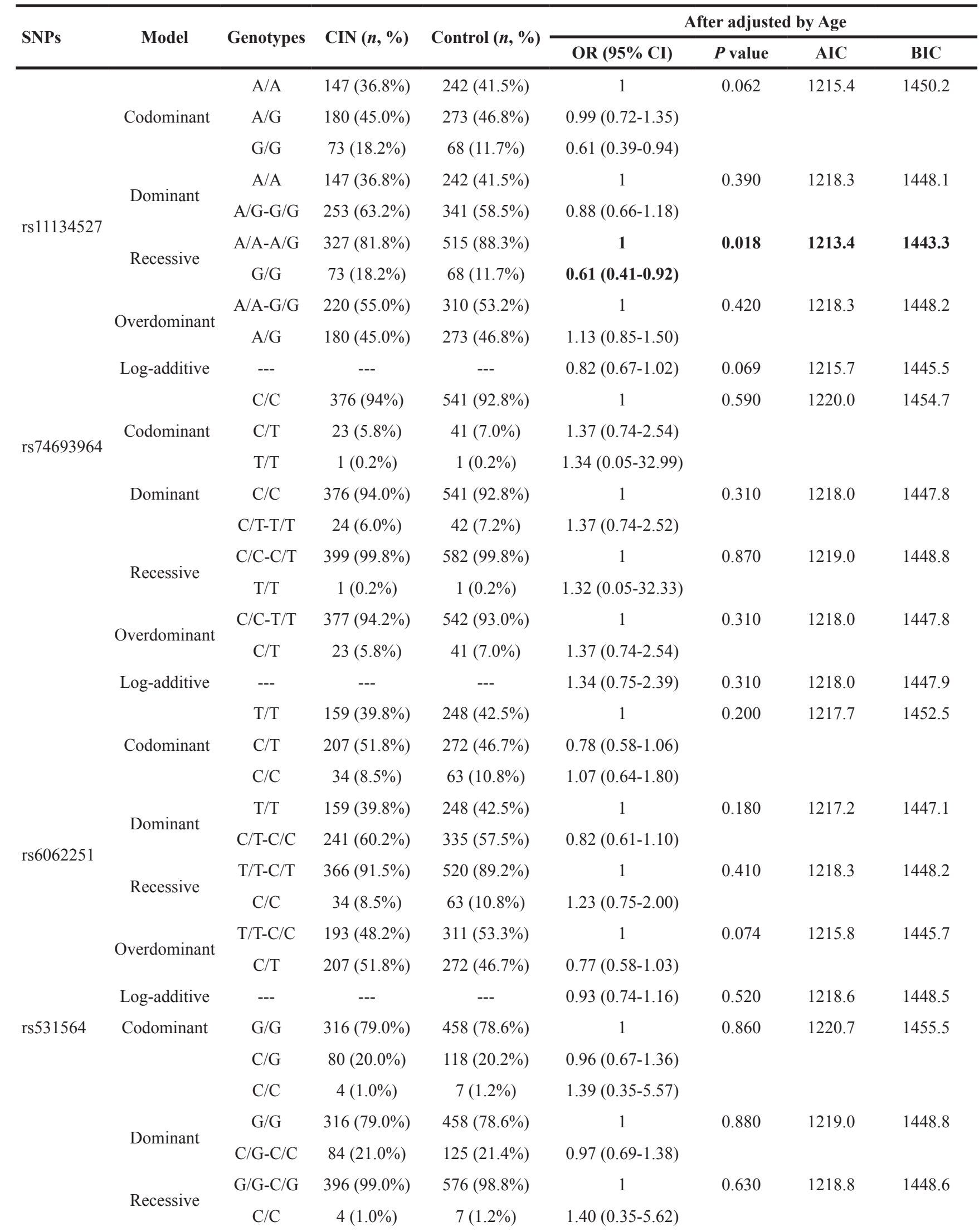

(Continued) 


\begin{tabular}{|c|c|c|c|c|c|c|c|c|}
\hline \multirow{2}{*}{ SNPs } & \multirow{2}{*}{ Model } & \multirow{2}{*}{ Genotypes } & \multirow{2}{*}{$\operatorname{CIN}(n, \%)$} & \multirow{2}{*}{ Control $(n, \%)$} & \multicolumn{4}{|c|}{ After adjusted by Age } \\
\hline & & & & & OR $(95 \%$ CI) & $P$ value & AIC & BIC \\
\hline \multirow{13}{*}{ rs1834306 } & \multirow{2}{*}{ Overdominant } & $\mathrm{G} / \mathrm{G}-\mathrm{C} / \mathrm{C}$ & $320(80.0 \%)$ & $465(79.8 \%)$ & 1 & 0.780 & 1218.9 & 1448.8 \\
\hline & & $\mathrm{C} / \mathrm{G}$ & $80(20.0 \%)$ & $118(20.2 \%)$ & $0.95(0.67-1.36)$ & & & \\
\hline & Log-additive & --- & --- & --- & $1.00(0.72-1.38)$ & 0.980 & 1219.0 & 1448.9 \\
\hline & \multirow{3}{*}{ Codominant } & $\mathrm{G} / \mathrm{G}$ & $119(29.8 \%)$ & $168(28.8 \%)$ & 1 & 0.750 & 1220.4 & 1455.2 \\
\hline & & $\mathrm{A} / \mathrm{G}$ & $190(47.5 \%)$ & $289(49.6 \%)$ & $1.13(0.81-1.58)$ & & & \\
\hline & & $\mathrm{A} / \mathrm{A}$ & $91(22.8 \%)$ & $126(21.6 \%)$ & $1.05(0.70-1.56)$ & & & \\
\hline & \multirow{2}{*}{ Dominant } & $\mathrm{G} / \mathrm{G}$ & $119(29.8 \%)$ & $168(28.8 \%)$ & 1 & 0.530 & 1218.6 & 1448.5 \\
\hline & & $\mathrm{A} / \mathrm{G}-\mathrm{A} / \mathrm{A}$ & $281(70.2 \%)$ & $415(71.2 \%)$ & $1.10(0.81-1.51)$ & & & \\
\hline & \multirow{2}{*}{ Recessive } & $\mathrm{G} / \mathrm{G}-\mathrm{A} / \mathrm{G}$ & $309(77.2 \%)$ & $457(78.4 \%)$ & 1 & 0.860 & 1219.0 & 1448.8 \\
\hline & & $\mathrm{A} / \mathrm{A}$ & $91(22.8 \%)$ & $126(21.6 \%)$ & $0.97(0.69-1.37)$ & & & \\
\hline & \multirow[t]{2}{*}{ Overdominant } & $\mathrm{G} / \mathrm{G}-\mathrm{A} / \mathrm{A}$ & $210(52.5 \%)$ & $294(50.4 \%)$ & 1 & 0.470 & 1218.5 & 1448.3 \\
\hline & & $\mathrm{A} / \mathrm{G}$ & $190(47.5 \%)$ & $289(49.6 \%)$ & $1.11(0.84-1.48)$ & & & \\
\hline & Log-additive & --- & --- & --- & $1.03(0.84-1.26)$ & 0.770 & 1218.9 & 1448.8 \\
\hline
\end{tabular}

Table 5: Different inheritance models analysis of the SNPs in miRNA genes in the comparison between CIN and cervical cancer groups

\begin{tabular}{|c|c|c|c|c|c|c|c|c|}
\hline \multirow{2}{*}{ SNPs } & \multirow{2}{*}{ Models } & \multirow{2}{*}{ Genotypes } & \multirow{2}{*}{ Cervical cancer $(n, \%)$} & \multirow{2}{*}{$\operatorname{CIN}(n, \%)$} & \multicolumn{4}{|c|}{ After adjusted by Age } \\
\hline & & & & & OR $(95 \%$ CI) & $P$ value & AIC & BIC \\
\hline \multirow{9}{*}{ rs11134527 } & \multirow{3}{*}{ Codominant } & $\mathrm{A} / \mathrm{A}$ & $223(36.6 \%)$ & $147(36.8 \%)$ & 1 & 0.290 & 1365.1 & 1615.8 \\
\hline & & $\mathrm{A} / \mathrm{G}$ & $294(48.3 \%)$ & $180(45.0 \%)$ & $0.89(0.66-1.19)$ & & & \\
\hline & & $\mathrm{G} / \mathrm{G}$ & $92(15.1 \%)$ & $73(18.2 \%)$ & $1.20(0.81-1.78)$ & & & \\
\hline & \multirow{2}{*}{ Dominant } & $\mathrm{A} / \mathrm{A}$ & $223(36.6 \%)$ & $147(36.8 \%)$ & 1 & 0.770 & 1365.5 & 1611.3 \\
\hline & & A/G-G/G & $386(63.4 \%)$ & $253(63.2 \%)$ & $0.96(0.73-1.27)$ & & & \\
\hline & \multirow{2}{*}{ Recessive } & $\mathrm{A} / \mathrm{A}-\mathrm{A} / \mathrm{G}$ & $517(84.9 \%)$ & $327(81.8 \%)$ & 1 & 0.170 & 1363.7 & 1609.5 \\
\hline & & $\mathrm{G} / \mathrm{G}$ & $92(15.1 \%)$ & $73(18.2 \%)$ & $1.28(0.90-1.84)$ & & & \\
\hline & \multirow{2}{*}{ Overdominant } & $\mathrm{A} / \mathrm{A}-\mathrm{G} / \mathrm{G}$ & $315(51.7 \%)$ & $220(55.0 \%)$ & 1 & 0.200 & 1363.9 & 1609.7 \\
\hline & & $\mathrm{A} / \mathrm{G}$ & $294(48.3 \%)$ & $180(45.0 \%)$ & $0.84(0.64-1.10)$ & & & \\
\hline \multirow{11}{*}{ rs74693964 } & Log-additive & --- & --- & --- & $1.05(0.87-1.27)$ & 0.600 & 1365.3 & 1611.1 \\
\hline & \multirow{3}{*}{ Codominant } & $\mathrm{C} / \mathrm{C}$ & $576(94.6 \%)$ & $376(94.0 \%)$ & 1 & 0.510 & 1366.2 & 1617 \\
\hline & & $\mathrm{C} / \mathrm{T}$ & $33(5.4 \%)$ & $23(5.8 \%)$ & $0.96(0.54-1.73)$ & & & \\
\hline & & $\mathrm{T} / \mathrm{T}$ & $0(0.0 \%)$ & $1(0.2 \%)$ & NA $(0.00-N A)$ & & & \\
\hline & \multirow{2}{*}{ Dominant } & $\mathrm{C} / \mathrm{C}$ & $576(94.6 \%)$ & $376(94.0 \%)$ & 1 & 1 & 1365.5 & 1611.4 \\
\hline & & $\mathrm{C} / \mathrm{T}-\mathrm{T} / \mathrm{T}$ & $33(5.4 \%)$ & $24(6.0 \%)$ & $1.00(0.56-1.78)$ & & & \\
\hline & \multirow{2}{*}{ Recessive } & $\mathrm{C} / \mathrm{C}-\mathrm{C} / \mathrm{T}$ & $609(100.0 \%)$ & $399(99.8 \%)$ & 1 & 0.250 & 1364.2 & 1610.1 \\
\hline & & $\mathrm{T} / \mathrm{T}$ & $0(0.0 \%)$ & $1(0.2 \%)$ & NA (0.00-NA) & & & \\
\hline & \multirow{2}{*}{ Overdominant } & $\mathrm{C} / \mathrm{C}-\mathrm{T} / \mathrm{T}$ & $576(94.6 \%)$ & $377(94.2 \%)$ & 1 & 0.890 & 1365.5 & 1611.4 \\
\hline & & $\mathrm{C} / \mathrm{T}$ & $33(5.4 \%)$ & $23(5.8 \%)$ & $0.96(0.54-1.72)$ & & & \\
\hline & Log-additive & --- & --- & --- & $1.04(0.60-1.82)$ & 0.890 & 1365.5 & 1611.4 \\
\hline
\end{tabular}




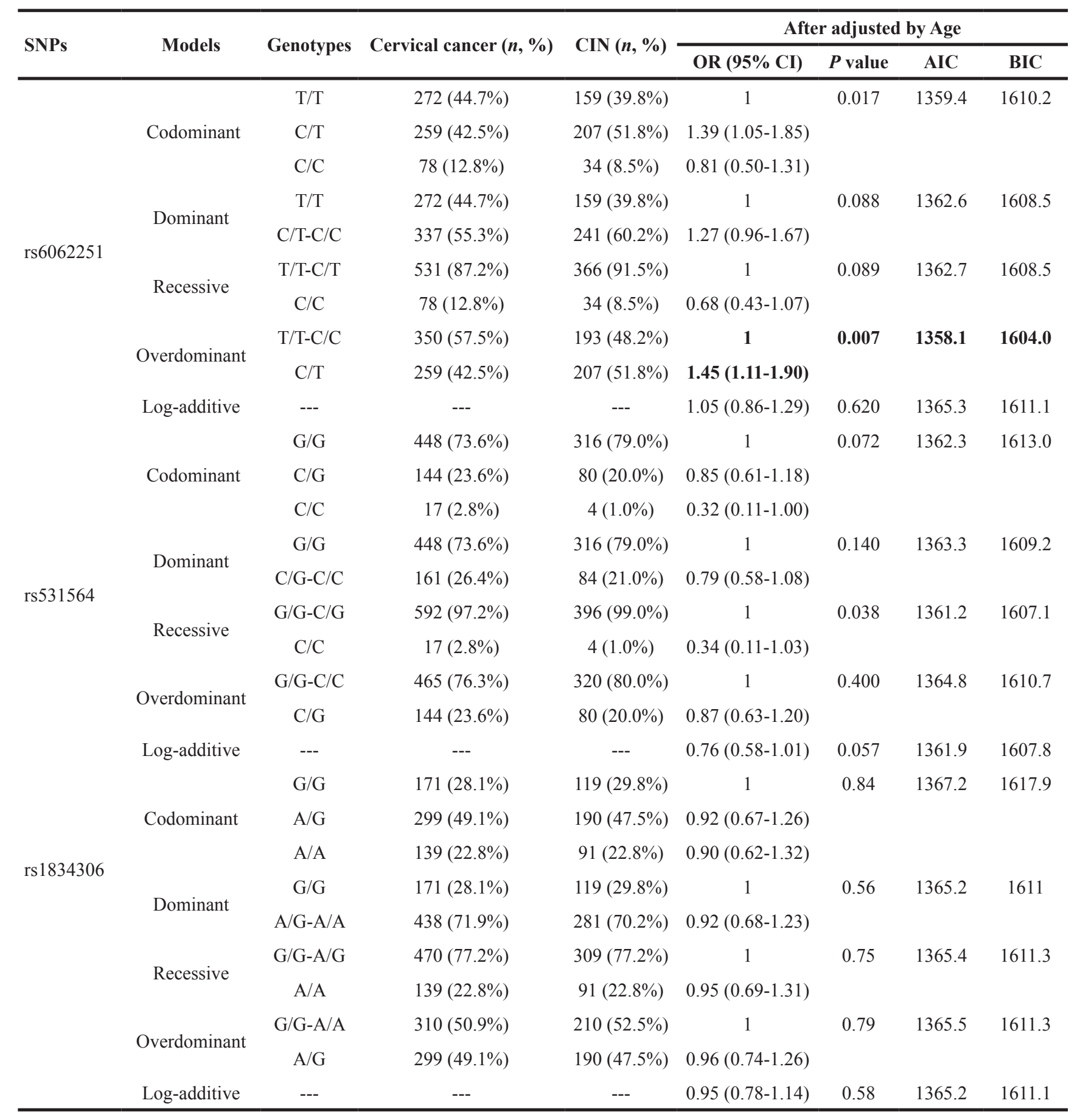

consistent with the results of Wu et al., showing that the $\mathrm{C}$ allele is a risk factor for cervical cancer [37]. However, there was no significant association of rs531564 with CIN in the present study. It is likely that this polymorphism in pri-miR-124-1 is only associated with cervical cancer but not CIN. The two different stages (CIN and cervical cancer) of cervical cancer have different nosogenesis; thus, the same SNP may play different roles in two different disease stages.

MiR-145, a tumour suppressor, has been implicated in the death-promoting regulatory loop of P53 [39]. The downregulation of miR-145 has been associated with aggressive progression and poor prognosis in cervical cancer [40]. In 2015, Chacon-Cortes et al reported the association of rs353291 in miR-145 with breast cancer susceptibility [41]. However, in the present study, we investigated the association of rs74693964, another SNP in near Gene-3 of miR-145, with cervical cancer in a Chinese population; no significant association of rs74693964 with CIN and cervical cancer was detected.

MiR-133a plays a crucial role in myoblast proliferation and differentiation. Recent studies have 
Table 6: Different inheritance models analysis of the SNPs in miRNA genes in the comparison between control and cervical cancer groups

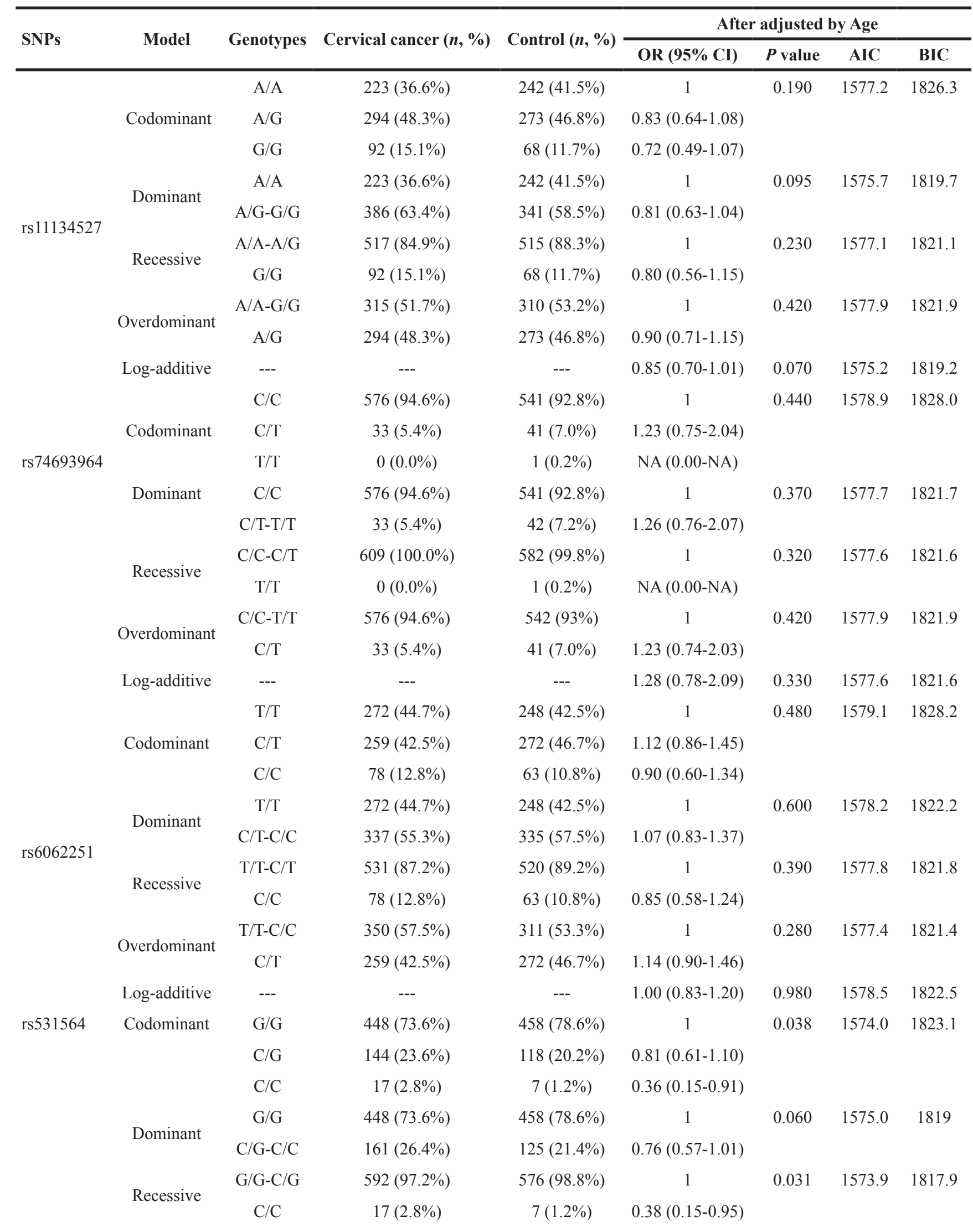

(Continued) 


\begin{tabular}{|c|c|c|c|c|c|c|c|c|}
\hline \multirow{2}{*}{ SNPs } & \multirow{2}{*}{ Model } & \multirow{2}{*}{ Genotypes } & \multirow{2}{*}{ Cervical cancer $(n, \%)$} & \multirow{2}{*}{ Control $(n, \%)$} & \multicolumn{4}{|c|}{ After adjusted by Age } \\
\hline & & & & & OR $(95 \%$ CI $)$ & $P$ value & AIC & BIC \\
\hline \multirow{13}{*}{ rs 1834306} & \multirow{2}{*}{ Overdominant } & $\mathrm{G} / \mathrm{G}-\mathrm{C} / \mathrm{C}$ & $465(76.3 \%)$ & $465(79.8 \%)$ & 1 & 0.23 & 1577.1 & 1821.1 \\
\hline & & $\mathrm{C} / \mathrm{G}$ & $144(23.6 \%)$ & $118(20.2 \%)$ & $0.84(0.62-1.12)$ & & & \\
\hline & Log-additive & --- & --- & --- & $0.75(0.58-0.96)$ & 0.022 & 1573.3 & 1817.3 \\
\hline & \multirow{3}{*}{ Codominant } & $\mathrm{G} / \mathrm{G}$ & $171(28.1 \%)$ & $168(28.8 \%)$ & 1 & 1 & 1580.5 & 1829.6 \\
\hline & & $\mathrm{A} / \mathrm{G}$ & $299(49.1 \%)$ & $289(49.6 \%)$ & $0.99(0.74-1.32)$ & & & \\
\hline & & $\mathrm{A} / \mathrm{A}$ & $139(22.8 \%)$ & $126(21.6 \%)$ & $0.99(0.70-1.41)$ & & & \\
\hline & \multirow{2}{*}{ Dominant } & $\mathrm{G} / \mathrm{G}$ & $171(28.1 \%)$ & $168(28.8 \%)$ & 1 & 0.93 & 1578.5 & 1822.5 \\
\hline & & $\mathrm{A} / \mathrm{G}-\mathrm{A} / \mathrm{A}$ & $438(71.9 \%)$ & $415(71.2 \%)$ & $0.99(0.75-1.30)$ & & & \\
\hline & \multirow{2}{*}{ Recessive } & $\mathrm{G} / \mathrm{G}-\mathrm{A} / \mathrm{G}$ & $470(77.2 \%)$ & $457(78.4 \%)$ & 1 & 0.99 & 1578.5 & 1822.5 \\
\hline & & $\mathrm{A} / \mathrm{A}$ & $139(22.8 \%)$ & $126(21.6 \%)$ & $1.00(0.74-1.35)$ & & & \\
\hline & \multirow{2}{*}{ Overdominant } & G/G-A/A & $310(50.9 \%)$ & $294(50.4 \%)$ & 1 & 0.93 & 1578.5 & 1822.5 \\
\hline & & $\mathrm{A} / \mathrm{G}$ & $299(49.1 \%)$ & $289(49.6 \%)$ & $0.99(0.77-1.26)$ & & & \\
\hline & Log-additive & --- & --- & --- & $1.00(0.84-1.19)$ & 0.96 & 1578.5 & 1822.5 \\
\hline
\end{tabular}

shown the downregulation of miR-133a in human cancers. Accumulating evidence has indicated that the restoration of miR-133a expression could induce the suppression of cell proliferation, migration and invasion, and tumour cell apoptosis [42-44], indicating that miR-133a might act as a tumour suppressor in human cancers, including cervical cancer [45]. Zhou et al reported that rs 8089787 and rs9948906 in miR-133a1 were associated with the risk of asthma in a Chinese Han population [46]. Paula et al analysed the association of rs 13040413 and rs200375711 in miR-133a2 with long QT syndrome and observed no association between the two SNPs with long QT syndrome [47]. In the present study, we investigated the association of rs6062251 in the near Gene-3 of miR-133a2 with the initiation and development of cervical cancer. These results showed that the genotypic frequencies were significantly different between control, CIN and cervical cancer groups. The inheritance analysis showed that $\mathrm{T} / \mathrm{T}-\mathrm{C} / \mathrm{C}$ genotype were correlated with increased risk of progression from $\mathrm{CIN}$ to cervical cancer in the overdominant model $(P=0.007, \mathrm{OR}=1.45 ; 95 \% \mathrm{CI}$ : 1.11 1.90).

In recent years, miR-100 has been reported to target numerous biomolecules associated with carcinogenesis, suggesting that miR-100 functions as both a tumour promoter and a tumour suppressor. In cervical cancer, miR-100 functions as a potential tumour suppressive miRNA involved in tumour occurrence, development and drug resistance [48]. Li et al. [49] reported the reduced expression of miR-100 in CIN and cervical cancer. Zhu et al. reported that a SNP in miR-100 was associated with various types of diseases (Table 7) [50]. In the present study, we did not observe any association of rs 1834306 in pri-miR-100 with the initiation and development of cervical cancer in a Chinese Han population. Similarly, Xiong et al. detected no relationship between rs 1834306 in pri-miR-100 and cervical cancer risk in a Chinese Han population (Table 7) [51].

In current study, our results showed the allele or genotype of given miRNA played different roles in normal tissue, CIN and/or cervical cancer. The reason for the discrepancies could be the onset of cervical cancer is a multistep process that means progression of cervical cancer is from normal tissue to invasive cervical cancer through a series increasing grades of squamous intraepithelial lesions [52]. Among this multistep process, the miRNAs expression and their targets have shown discrepancies. For example, the expression of miR-145, miR-218 and miR-100 was progressive reduced and down-regulated from CIN 1 to 3 and cervical cancer versus normal tissue [53-55]. Furthermore, the miRNA expression alternation could change their targets function. In 2012, Qin et al. reported that miR-133b expression in CIN 2, 3 and cervical carcinoma had a gradual raise, which increased AKT and MAPKs (ERK1 and ERK2) phosphorylation augmenting tumorigenesis [56]. Their finding indicated miRNAs could play different roles in the progression of cervical cancer. Therefore, the different alleles or genotypes of SNPs in these miRNAs could function differently in the multistep stages of cervical cancer by altering their expression level and the binding affinity between them and their targets.

In summary, we investigated the association of the SNPs in five anti-oncogene miRNAs (pri-miR-218-2, pri-miR-145, pri-miR-133a2, pri-miR124-1 and primiR-100) with the CIN and cervical cancer in a Chinese Han population. The results showed that the A allele of rs11134527 in pri-miR-218-2 maybe associated with 
Table 7: The characteristics of five SNPs found in miRNAs and their related association studies with cancers

\begin{tabular}{|c|c|c|c|c|c|c|c|}
\hline miRNA locus & Function & SNPs & Alleles (case/control) & & Diseases/reference & Population(region) & $P$ value \\
\hline \multirow[t]{4}{*}{ Pri-miR-218-2 } & Anti-oncogene & rs 11134527 & A & G & & & \\
\hline & & & $1321 / 1538$ & $897 / 1012$ & ESCC [26] & $\begin{array}{c}\text { Han Chinese } \\
\text { (Taizhou and Shanghai) }\end{array}$ & 0.595 \\
\hline & & & $346 / 599$ & $258 / 427$ & $\mathrm{HCC}$ [27] & $\begin{array}{l}\text { Han Chinese } \\
\text { (Sichuan) }\end{array}$ & 0.670 \\
\hline & & & $1928 / 1662$ & $1202 / 1120$ & Cervical Cancer [28] & $\begin{array}{l}\text { Han Chinese } \\
\text { (Shanghai) }\end{array}$ & 0.145 \\
\hline \multirow[t]{4}{*}{ Pri-miR-124-1 } & Anti-oncogene & rs531564 & $\mathrm{C}$ & G & & & \\
\hline & & & $1901 / 2151$ & $317 / 399$ & ESCC [26] & $\begin{array}{c}\text { Han Chinese } \\
\text { (Taizhou and Shanghai) }\end{array}$ & 0.191 \\
\hline & & & $290 / 434$ & $26 / 86$ & Cervical Cancer [37] & $\begin{array}{l}\text { Han Chinese ( } \\
\text { Zhengzhou) }\end{array}$ & 0.001 \\
\hline & & & $197 / 353$ & $17 / 63$ & Cervical Cancer [38] & $\begin{array}{l}\text { Han Chinese } \\
\text { (Guangdong) }\end{array}$ & 0.014 \\
\hline \multirow[t]{2}{*}{ Pri-miR-145 } & Anti-oncogene & rs74693964 & $\mathrm{C}$ & $\mathrm{T}$ & & & \\
\hline & & & no reference & no reference & no reference & no reference & no reference \\
\hline \multirow[t]{2}{*}{ Pri-miR-133a2 } & Anti-oncogene & rs6062251 & $\mathrm{C}$ & $\mathrm{T}$ & & & \\
\hline & & & no reference & no reference & no reference & no reference & no reference \\
\hline \multirow[t]{3}{*}{ Pri-miR-100 } & Anti-oncogene & rs1834306 & A & G & & & \\
\hline & & & $217 / 189$ & $279 / 399$ & $\operatorname{ESCC}[50]$ & Kazakh Chinese (Xinjiang) & $8.37 \times 10^{-5}$ \\
\hline & & & $92 / 377$ & $114 / 457$ & Cervical Cancer [51] & $\begin{array}{l}\text { Han Chinese } \\
\text { (Guangzhou) }\end{array}$ & 0.892 \\
\hline
\end{tabular}

decreased risk of cervical cancer $(\mathrm{OR}=0.836$; $95 \% \mathrm{CI}$ : $0.708 \sim 0.988)$ and may be a protective factor for the initiation of $\mathrm{CIN}(\mathrm{OR}=0.786$; 95\%CI: 0.653 0.946), and the $\mathrm{C}$ allele of rs531564 in pri-miR-124-1 may be associated with increased risk of cervical cancer $(\mathrm{OR}=1.341 ; 95 \% \mathrm{CI}: 1.054-1.706)$ and maybe a risk factor for the progress form $\mathrm{CIN}$ to cervical cancer $(\mathrm{OR}=1.385$; 95\% CI: $1.054-1.819$ ) in a Chinese Han population.

\section{MATERIALS AND METHODS}

\section{Ethics statement}

The present study was approved through the Institutional Review Board of the 3rd Affiliated Hospital of Kunming Medical University. The methods of this investigation were performed in accordance with the approved guidelines and principles expressed in the Helsinki Declaration of 1975, which was revised in 2008. All participants provided written informed consent.

\section{Subjects}

A total of $400 \mathrm{CIN}$ and 609 cervical cancer patients were recruited at the 3rd Affiliated Hospital of Kunming Medical University from 2011 to 2015. The diagnosis of CIN and cervical cancer was confirmed by pathological examination according to "Diagnosis and Treatment Obstetrics and Gynaecology" and FIGO stage (International Federation of Gynaecology and Obstetrics, 2009). Subjects with oncotherapy history or other malignancy or incomplete clinical data were excluded from the present study. During the same period, 583 healthy women undergoing routine health check-ups at the same hospital were designated as the control group. The inclusion criteria of control subjects were HPV-negative women without any cervical lesions. All participants were self-reported as ethnically Han.

\section{Genomic DNA extracted}

Genomic DNA was extracted from peripheral lymphocytes using the QIAamp Blood Mini Kit (Qiagen, Hilden, German).

\section{MicroRNA selection and sequencing}

A total of nineteen miRNAs associated with cervical cancer [18] were sequenced (the sequencing ranged from $200 \mathrm{bp}$ upstream to 200bp downstream of miRNA genes) in 50 healthy individuals to search for SNPs (miR-1241, miR-9-2, miR-100, miR-101-2, miR-214, miR-218-1, 
miR-218-2, miR-424, miR-7-1, miR-7-2, miR-7-3, miR21, miR-23B, miR-31, miR-127, miR-133a2, miR-145, miR-205 and miR-3529).

\section{SNP genotyping using TaqMan assay method}

SNPs, namely, rs11134527 in pri-miR-218-2, rs74693964 in pri-miR145, rs6062251 in pri-miR-133a2, rs531564 in pri-miR-124-1 and rs1834306 in pri-miR-100, were genotyped through PCR amplification using the TaqMan assay. The TaqMan assays including the primers and probes were designed and ordered by Applied Biosystems (https://bioinfo.appliedbiosystems.com/ genome-database/snp-genotyping.html). Briefly, these SNPs were genotyped in 384-well plates using TaqMan assays in the QuantStudio 6 Flex Fast Real-Time PCR System. Amplification was performed in a 5 - $\mu$ l reaction volume consisting of $2.5 \mu \mathrm{l} 2 \times$ TaqMan Master Mix, $0.125 \mu \mathrm{l} 40 \times$ Primer and TaqMan Probe (FAM VIC) dye mix, $1.375 \mu \mathrm{lddH_{2 }} \mathrm{O}$, and $1 \mu \mathrm{l}$ template DNA (substituted by equivalent $\mathrm{ddH}_{2} \mathrm{O}$ in negative control). The following PCR cycle conditions were used: $95^{\circ} \mathrm{C}$ for $10 \mathrm{~min}$; PCR stage $92^{\circ} \mathrm{C}$ for $10 \mathrm{~s}$ and $60^{\circ} \mathrm{C}$ for $1 \mathrm{~min}$ repeated in 40 cycles. Data acquisitions and analysis were performed on QuantStudio ${ }^{\text {TM }}$ real-time PCR software. To identify the accuracy of SNP genotyping using the TaqMan assay, three positive controls and one negative control were simultaneously genotyped using the TaqMan assay.

\section{Statistical analysis}

The allelic and genotypic frequencies of the SNPS were calculated using a direct-counting method. HardyWeinberg equilibrium (HWE) was tested for the SNPs in the control group. A $\chi^{2}$ test was used to determine differences in allelic and genotypic frequencies, and the odds ratios (OR) with associated $95 \%$ confidence intervals (CIs) of allele and genotype-specific risks were calculated. The ages among different groups were compared using one-way ANOVA, followed by the LSD test for multiple comparisons correction. The association of each SNP with CIN and cervical cancer was analysed for the model of inheritance using SNPStats software [57]. The Akaike information criterion (AIC) and Bayesian information criterion (BIC) were used to determine the best-fit model for each SNP. The model with the smallest AIC and BIC values corresponds to minimal expected entropy. The statistical analyses were performed using SPSS 13 (Chicago, IL). A $P$ value less than 0.05 was considered statistically significant.

\section{Abbreviations}

SNP: single nucleotide polymorphisms; miRNA: microRNA; CIN: cervical intraepithelial neoplasia; HPV: human papillomavirus; HWE: Hardy-Weinberg equilibrium; OR: odds ratios; CI: confidence intervals;
AIC: Akaike information criterion; BIC: Bayesian information criterion.

\section{Author contributions}

Yao Yufeng, Shi Li and Yang Hongying designed the current study; Li Chuanyin, Wang Xiaona and Zhang Yu performed the DNA extracting, sequencing and SNP genotyping; Yan Zhiling, Zhang Yu, Liu Shuyuan, Yang jie and Hong Chao collected the blood samples and the clinical data; Li Chuanyin drafted the manuscript; Yao Yufeng, Shi Li and Yang Hongying revised the manuscript critically. All authors agreed the final version of the manuscript.

\section{ACKNOWLEDGMENTS}

We are grateful for participation of the patients and control subjects in this study. Appreciation is also owned to all physicians and nursing staff of the $3^{\text {rd }}$ Affiliated Hospital of Kunming Medical University.

\section{CONFLICTS OF INTEREST}

The authors declare no conflicts of interest.

\section{FUNDING}

This work was supported by a grant from the National Natural Science Foundation of China (81573206 and 31270030), Yunnan Applied Basic Research Projects (2016FA034), The PUMC Youth Fund (3332015149), Foundation Program of Yunnan Gynecologic Oncology Research Centre (2014NS032), Special Funds for highlevel health talents of Yunnan Province (D-201669 and L-201615) and CAMS Innovation Fund for Medical Sciences (2016-12M-2-001). The funders had no role in study design, data collection and analysis, decision to publish, or preparation of the manuscript.

\section{REFERENCES}

1. Jemal A, Bray F, Center MM, Ferlay J, Ward E, Forman D. Global cancer statistics. CA Cancer J Clin. 2011; 61: 69-90. https://doi.org/10.3322/caac.20107.

2. Reshmi G, Pillai MR. Beyond HPV: oncomirs as new players in cervical cancer. FEBS Lett. 2008; 582: 4113-6. https://doi.org/10.1016/j.febslet.2008.11.011.

3. de Freitas AC, Gurgel AP, Chagas BS, Coimbra EC, do Amaral CM. Susceptibility to cervical cancer: an overview. Gynecol Oncol. 2012; 126: 304-11. https://doi. org/10.1016/j.ygyno.2012.03.047.

4. Fang J, Li Y, Zhang J, Yan M, Li J, Bao S, Jin T. Correlation between polymorphisms in microRNA-regulated genes and cervical cancer susceptibility in a Xinjiang Uygur 
population. Oncotarget. 2017; 8: 31758-64. https://doi. org/10.18632/oncotarget.15970.

5. Zeng X, Zhang Y, Yue T, Zhang T, Wang J, Xue Y, An R. Association between XRCC1 polymorphisms and the risk of cervical cancer: a meta-analysis based on 4895 subjects. Oncotarget. 2017; 8: 2249-60. https://doi.org/10.18632/ oncotarget.13663.

6. Friedman RC, Farh KK, Burge CB, Bartel DP. Most mammalian mRNAs are conserved targets of microRNAs. Genome Res. 2009; 19: 92-105. https://doi.org/10.1101/ gr.082701.108.

7. Bartel DP. MicroRNAs: genomics, biogenesis, mechanism, and function. Cell. 2004; 116: 281-97.

8. Sachdeva M, Mo YY. miR-145-mediated suppression of cell growth, invasion and metastasis. Am J Transl Res. 2010; 2: 170-80.

9. Winter J, Diederichs S. MicroRNA biogenesis and cancer. Methods Mol Biol. 2011; 676: 3-22. https://doi. org/10.1007/978-1-60761-863-8_1.

10. Nicoloso MS, Spizzo R, Shimizu M, Rossi S, Calin GA. MicroRNAs--the micro steering wheel of tumour metastases. Nat Rev Cancer. 2009; 9: 293-302. https://doi. org/10.1038/nrc2619.

11. Zheng ZM, Wang X. Regulation of cellular miRNA expression by human papillomaviruses. Biochim Biophys Acta. 2011; 1809: 668-77. https://doi.org/10.1016/j. bbagrm.2011.05.005.

12. Servin-Gonzalez LS, Granados-Lopez AJ, Lopez JA. Families of microRNAs expressed in clusters regulate cell signaling in cervical cancer. Int J Mol Sci. 2015; 16: 12773 90. https://doi.org/10.3390/ijms160612773.

13. Banno K, Iida M, Yanokura M, Kisu I, Iwata T, Tominaga E, Tanaka K, Aoki D. MicroRNA in cervical cancer: oncomiRs and tumor suppressor miRs in diagnosis and treatment. ScientificWorldJournal. 2014; 2014: 178075. https://doi. org/10.1155/2014/178075.

14. Liu H, Zhou Y, Liu Q, Xiao G, Wang B, Li W, Ye D, Yu S. Association of miR-608 rs4919510 polymorphism and cancer risk: a meta-analysis based on 13,664 subjects. Oncotarget. 2017; 8: 37023-31. https://doi.org/10.18632/ oncotarget.9509.

15. Yin Z, Cui Z, Ren Y, Xia L, Li H, Zhou B. MiR-146a polymorphism correlates with lung cancer risk in Chinese nonsmoking females. Oncotarget. 2017; 8: 2275-83. https:// doi.org/10.18632/oncotarget.13722.

16. Yang J, Zhang Z, Guo W, Ma Y, Emin RM, Abudubari K, Hayrat G, Wali H, Qi X, Liu C, Ma M, Nurbek P. Single nucleotide polymorphisms in microRNA genes are associated with cervical cancer susceptibility in a population from Xinjiang Uygur. Oncotarget. 2016; 7: 71447-54. https://doi.org/10.18632/oncotarget.12212.

17. Wang S, Cao X, Ding B, Chen J, Cui M, Xu Y, Lu X, Zhang Z, He A, Jin H. The rs767649 polymorphism in the promoter of miR-155 contributes to the decreased risk for cervical cancer in a Chinese population. Gene. 2016; 595: 109-14. https://doi.org/10.1016/j.gene.2016.10.002.

18. He Y, Lin J, Ding Y, Liu G, Luo Y, Huang M, Xu C, Kim TK, Etheridge A, Lin M, Kong D, Wang K. A systematic study on dysregulated microRNAs in cervical cancer development. Int J Cancer. 2016; 138: 1312-27. https://doi. org/10.1002/ijc.29618.

19. Xie K, Chen M, Zhu M, Wang C, Qin N. A polymorphism in miR-1262 regulatory region confers the risk of lung cancer in Chinese population. 2017; 141: 958-66. https:// doi.org/10.1002/ijc.30788.

20. Min P, Li W, Zeng D, Ma Y, Xu D, Zheng W, Tang F, Chen J, Shi J, Hu H, Wang J, Yang D, Liu J, et al. A single nucleotide variant in microRNA-1269a promotes the occurrence and process of hepatocellular carcinoma by targeting to oncogenes SPATS2L and LRP6. Bull Cancer. 2017; 104: 311-20. https://doi.org/10.1016/j. bulcan.2016.11.021.

21. Yamamoto N, Kinoshita T, Nohata N, Itesako T, Yoshino H, Enokida H, Nakagawa M, Shozu M, Seki N. Tumor suppressive microRNA-218 inhibits cancer cell migration and invasion by targeting focal adhesion pathways in cervical squamous cell carcinoma. Int J Oncol. 2013; 42: 1523-32. https://doi.org/10.3892/ijo.2013.1851.

22. Alajez NM, Lenarduzzi M, Ito E, Hui AB, Shi W, Bruce J, Yue S, Huang SH, Xu W, Waldron J, O'Sullivan B, Liu FF. MiR-218 suppresses nasopharyngeal cancer progression through downregulation of survivin and the SLIT2-ROBO1 pathway. Cancer Res. 2011; 71: 2381-91. https://doi. org/10.1158/0008-5472.can-10-2754.

23. Uesugi A, Kozaki K, Tsuruta T, Furuta M, Morita K, Imoto I, Omura K, Inazawa J. The tumor suppressive microRNA miR-218 targets the mTOR component Rictor and inhibits AKT phosphorylation in oral cancer. Cancer Res. 2011; 71: 5765-78. https://doi.org/10.1158/0008-5472.can-11-0368.

24. Tie J, Pan Y, Zhao L, Wu K, Liu J, Sun S, Guo X, Wang B, Gang Y, Zhang Y, Li Q, Qiao T, Zhao Q, et al. MiR218 inhibits invasion and metastasis of gastric cancer by targeting the Robo1 receptor. PLoS Genet. 2010; 6: e1000879. https://doi.org/10.1371/journal.pgen.1000879.

25. Zhu K, Ding H, Wang W, Liao Z, Fu Z, Hong Y, Zhou Y, Zhang CY, Chen X. Tumor-suppressive miR-218-5p inhibits cancer cell proliferation and migration via EGFR in non-small cell lung cancer. Oncotarget. 2016; 7: 28075 85. https://doi.org/10.18632/oncotarget.8576.

26. Zhang J, Huang X, Xiao J, Yang Y, Zhou Y, Wang X, Liu Q, Yang J, Wang M, Qiu L, Zheng Y, Zhang P, Li J, et al. Pri-miR-124 rs531564 and pri-miR-34b/c rs4938723 polymorphisms are associated with decreased risk of esophageal squamous cell carcinoma in Chinese populations. PLoS One. 2014; 9: e100055. https://doi. org/10.1371/journal.pone.0100055.

27. Zhang LS, Liang WB, Gao LB, Li HY, Li LJ, Chen PY, Liu Y, Chen TY, Han JG, Wei YG, Zhang L. Association between pri-miR-218 polymorphism and risk of 
hepatocellular carcinoma in a Han Chinese population. DNA Cell Biol. 2012; 31: 761-5. https://doi.org/10.1089/ dna.2011.1326.

28. Shi TY, Chen XJ, Zhu ML, Wang MY, He J, Yu KD, Shao ZM, Sun MH, Zhou XY, Cheng X, Wu X, Wei Q. A pri-miR-218 variant and risk of cervical carcinoma in Chinese women. BMC Cancer. 2013; 13: 19. https://doi. org/10.1186/1471-2407-13-19.

29. Liu K, Zhao H, Yao H, Lei S, Lei Z, Li T, Qi H. MicroRNA-124 regulates the proliferation of colorectal cancer cells by targeting iASPP. Biomed Res Int. 2013; 2013: 867537. https://doi.org/10.1155/2013/867537.

30. Han ZB, Yang Z, Chi Y, Zhang L, Wang Y, Ji Y, Wang J, Zhao H, Han ZC. MicroRNA-124 suppresses breast cancer cell growth and motility by targeting CD151. Cell Physiol Biochem. 2013; 31: 823-32. https://doi. org/10.1159/000350100.

31. Yamane K, Jinnin M, Etoh T, Kobayashi Y, Shimozono N, Fukushima S, Masuguchi S, Maruo K, Inoue Y, Ishihara T, Aoi J, Oike Y, Ihn H. Down-regulation of miR-124/214 in cutaneous squamous cell carcinoma mediates abnormal cell proliferation via the induction of ERK. J Mol Med (Berl). 2013; 91: 69-81. https://doi.org/10.1007/ s00109-012-0935-7.

32. Wan HY, Li QQ, Zhang Y, Tian W, Li YN, Liu M, Li X, Tang H. MiR-124 represses vasculogenic mimicry and cell motility by targeting amotL1 in cervical cancer cells. Cancer Lett. 2014; 355: 148-58. https://doi.org/10.1016/j. canlet.2014.09.005.

33. Zhang X, Cai D, Meng L, Wang B. MicroRNA-124 inhibits proliferation, invasion, migration and epithelialmesenchymal transition of cervical carcinoma cells by targeting astrocyte-elevated gene-1. Oncol Rep. 2016; 36: 2321-8. https://doi.org/10.3892/or.2016.5025.

34. Jimenez-Wences H, Martinez-Carrillo DN, Peralta-Zaragoza O, Campos-Viguri GE, Hernandez-Sotelo D, JimenezLopez MA, Munoz-Camacho JG, Garzon-Barrientos VH, Illades-Aguiar B, Fernandez-Tilapa G. Methylation and expression of miRNAs in precancerous lesions and cervical cancer with HPV16 infection. Oncol Rep. 2016; 35: 2297 305. https://doi.org/10.3892/or.2016.4583.

35. Qi L, Hu Y, Zhan Y, Wang J, Wang BB, Xia HF, Ma X. A SNP site in pri-miR-124 changes mature miR-124 expression but no contribution to Alzheimer's disease in a Mongolian population. Neurosci Lett. 2012; 515: 1-6. https://doi.org/10.1016/j.neulet.2012.02.061.

36. Locke JM, Lango Allen H, Harries LW. A rare SNP in premiR-34a is associated with increased levels of miR-34a in pancreatic beta cells. Acta Diabetologica. 2013; 51: 325-9. https://doi.org/10.1007/s00592-013-0499-1.

37. $\mathrm{Wu} \mathrm{H}$, Zhang J. miR-124 rs531564 polymorphism influences genetic susceptibility to cervical cancer. Int J Clin Exp Med. 2014; 7: 5847-51.
38. Xiong X, Cheng J, Liu X, Tang S, Luo X. [Correlation analysis between miR-124 rs531564 polymorphisms and susceptibility to cervical cancer]. [Article in Chinese]. Nan Fang Yi Ke Da Xue Xue Bao. 2014; 34: 210-3.

39. Spizzo R, Nicoloso MS, Lupini L, Lu Y, Fogarty J, Rossi S, Zagatti B, Fabbri M, Veronese A, Liu X, Davuluri R, Croce CM, Mills G, et al. miR-145 participates with TP53 in a death-promoting regulatory loop and targets estrogen receptor-alpha in human breast cancer cells. Cell Death Differ. 2010; 17: 246-54. https://doi.org/10.1038/ cdd.2009.117.

40. Wang Q, Qin J, Chen A, Zhou J, Liu J, Cheng J, Qiu J, Zhang J. Downregulation of microRNA-145 is associated with aggressive progression and poor prognosis in human cervical cancer. Tumour Biol. 2015; 36: 3703-8. https://doi. org/10.1007/s13277-014-3009-3.

41. Chacon-Cortes D, Smith RA, Haupt LM, Lea RA, Youl $\mathrm{PH}$, Griffiths LR. Genetic association analysis of miRNA SNPs implicates MIR145 in breast cancer susceptibility. BMC Med Genet. 2015; 16: 107. https://doi.org/10.1186/ s12881-015-0248-0.

42. Kojima S, Chiyomaru T, Kawakami K, Yoshino H, Enokida H, Nohata N, Fuse M, Ichikawa T, Naya Y, Nakagawa M, Seki N. Tumour suppressors miR-1 and miR-133a target the oncogenic function of purine nucleoside phosphorylase (PNP) in prostate cancer. Br J Cancer. 2012; 106: 405-13. https://doi.org/10.1038/bjc.2011.462.

43. Dong Y, Zhao J, Wu CW, Zhang L, Liu X, Kang W, Leung WW, Zhang N, Chan FK, Sung JJ, Ng SS, Yu J. Tumor suppressor functions of miR-133a in colorectal cancer. Mol Cancer Res. 2013; 11: 1051-60. https://doi. org/10.1158/1541-7786.mcr-13-0061.

44. Nohata N, Hanazawa T, Kikkawa N, Mutallip M, Fujimura L, Yoshino H, Kawakami K, Chiyomaru T, Enokida H, Nakagawa M, Okamoto Y, Seki N. Caveolin-1 mediates tumor cell migration and invasion and its regulation by miR-133a in head and neck squamous cell carcinoma. Int $\mathrm{J}$ Oncol. 2011; 38: 209-17.

45. Song X, Shi B, Huang K, Zhang W. miR-133a inhibits cervical cancer growth by targeting EGFR. Oncol Rep. 2015; 34: 1573-80. https://doi.org/10.3892/or.2015.4101.

46. Zhou PP, Li Y, Ma ZD, Li ZY, Chen FY, Jiang YX. Single nucleotide polymorphisms in the promoter region of mir133a-1 and in pre-mir-152 rs1707 may contribute to the risk of asthma in a Chinese Han population. Eur Rev Med Pharmacol Sci. 2016; 20: 2642-9.

47. Hedley PL, Carlsen AL, Christiansen KM, Kanters JK, Behr ER, Corfield VA, Christiansen M. MicroRNAs in cardiac arrhythmia: DNA sequence variation of MiR-1 and MiR133A in long QT syndrome. Scand J Clin Lab Invest. 2014; 74: 485-91. https://doi.org/10.3109/00365513.2014.905696.

48. Dai Y, Xie CH, Neis JP, Fan CY, Vural E, Spring PM. MicroRNA expression profiles of head and neck squamous 
cell carcinoma with docetaxel-induced multidrug resistance. Head Neck. 2011; 33: 786-91. https://doi.org/10.1002/ hed. 21540 .

49. Li BH, Zhou JS, Ye F, Cheng XD, Zhou CY, Lu WG, Xie $\mathrm{X}$. Reduced miR-100 expression in cervical cancer and precursors and its carcinogenic effect through targeting PLK1 protein. Eur J Cancer. 2011; 47: 2166-74. https://doi. org/10.1016/j.ejca.2011.04.037.

50. Zhu J, Yang L, You W, Cui X, Chen Y, Hu J, Liu W, Li S, Song X, Wei Y, Zhang W, Li F. Genetic variation in miR-100 rs1834306 is associated with decreased risk for esophageal squamous cell carcinoma in Kazakh patients in northwest China. Int J Clin Exp Pathol. 2015; 8: 7332-40.

51. Xiong XD, Luo XP, Cheng J, Liu X, Li EM, Zeng LQ. A genetic variant in pre-miR-27a is associated with a reduced cervical cancer risk in southern Chinese women. Gynecol Oncol. 2014; 132: 450-4. https://doi.org/10.1016/j. ygyno.2013.12.030.

52. Doorbar J. Molecular biology of human papillomavirus infection and cervical cancer. Clin Sci (Lond). 2006; 110: 525-41. https://doi.org/10.1042/cs20050369.

53. Martinez I, Gardiner AS, Board KF, Monzon FA, Edwards RP, Khan SA. Human papillomavirus type 16 reduces the expression of microRNA-218 in cervical carcinoma cells. Oncogene. 2008; 27: 2575-82. https://doi.org/10.1038/ sj.onc. 1210919.

54. Pereira PM, Marques JP, Soares AR, Carreto L, Santos MA. MicroRNA expression variability in human cervical tissues. PLoS One. 2010; 5: e11780. https://doi.org/10.1371/journal. pone. 0011780 .

55. Granados Lopez AJ, Lopez JA. Multistep model of cervical cancer: participation of miRNAs and coding genes. Int $\mathrm{J}$ Mol Sci. 2014; 15: 15700-33. https://doi.org/10.3390/ ijms 150915700 .

56. Qin W, Dong P, Ma C, Mitchelson K, Deng T, Zhang L, Sun Y, Feng X, Ding Y, Lu X, He J, Wen H, Cheng J. MicroRNA-133b is a key promoter of cervical carcinoma development through the activation of the ERK and AKT1 pathways. Oncogene. 2012; 31: 4067-75. https://doi. org/10.1038/onc.2011.561.

57. Sole X, Guino E, Valls J, Iniesta R, Moreno V. SNPStats: a web tool for the analysis of association studies. Bioinformatics. 2006; 22: 1928-9. https://doi.org/10.1093/ bioinformatics/bt1268. 